\title{
The Role of Dispositional Optimism, Upward and Downward Counterfactual Thinking towards Student Persistence in Joining Competitions
}

\author{
Maria Gracia Amara Pawitra1 ${ }^{* 1}$, Wahyu Jati Anggoro ${ }^{2}$ \\ ${ }^{1,2}$ Faculty of Psychology, Universitas Gadjah Mada \\ 11 February $2021 \quad 11$ May 202130 August 2021
}

\begin{abstract}
Persistence is a key element contributing to college students' success in an academic competition. We argue that dispositional optimism, and upward and downward counterfactual thinking have influence in determining individuals' persistence. This cross-sectional study aimed to examine the role of dispositional optimism, upward and downward counterfactual thinking among persistence of student participants in university competitions. It employed quantitative methods and data were collected through the use of Dispositional Optimism Scale, Counterfactual Thinking Scale, and Persistence Scale. College students $(\mathrm{N}=204)$ who have competed in university competitions were recruited using a non-probability sampling method. Multiple regression assisted the data analysis process. Result showed that both dispositional optimism and upward counterfactual thinking simultaneously predicted students' persistence. However, downward counterfactual thinking was unable to predict the students' persistence. The research suggests that student competitors should enhance their optimism by developing positive thoughts concerning future competitions, as well as forming upward counterfactual thinking in subsequent competitions.
\end{abstract}

Keywords: counterfactual thinking; dispositional optimism; persistence

\section{Background}

Persistence is a crucial element that contributes to college students' success in university competitions (Czaja \& Cummings, 2009). Meanwhile, there are plenty types of prestigious student competitions from national to international level. Both academic and non-academic student competitions give students the opportunity to strengthen their curriculum vitae in order to increase their chances of success in the future job hunting. Successful competition may encourage individuals to acquire success in future competitions. In contrast, failure may impair persistence and lead to weaker motivation to compete (Czaja \& Cummings, 2009). This level of motivation may also affect students' academic achievement (Steinmayr \& Spinath, 2009) and their positive mental health (Huang et al., 2016).Therefore, it is very important to examine the factors that influence student persistence in joining competitions

Persistence has been studied in several context but there has not been any research investigating individual factors, especially optimism and counterfactual thinking, that determine student persistence in academic context. For example, Kamusoko and Pemberton (2013), Reisinger (2016), Brecht and Burnett (2019) conducted research concerning persistence among athletes in non-academic field. Three of the following research investigated persistence in relation to academic field but did not investigate about student participation. Le Bars et al. (2009) suggested that the social environment

${ }^{*}$ Address for correspondence: graciaamara@mail.ugm.ac.id 
affects persistence of athletes. However this research does not discuss the individual factors that may affect persistence.

Barney (1996) attempted to investigate individual elements influencing persistence in case studies among athletes participating in the 1932 Los Angeles Olympic Games. However, the study result is difficult to be generalized due to the small sample size and its outdated period. Recent research concerning individual elements in persistence was conducted by Rottensteiner et al. (2015) that highlighted the role of goal orientation. Research by Calvo et al. (2010) found that self-motivation and power orientation, competence, and involvement play a role in persistence by Segerstrom (2007) and Markman and McMullen (2003) as an individual variable affecting persistence.

Some research has shown that optimism affects academic persistence among undergraduate students (Aspinwall \& Richter, 1999; Nes et al., 2005; Tenney et al., 2015). However, these studies used an experimental approach of which the outcome was a result of manipulation, and not from an actual field context. Non-experimental correlational studies were conducted by Adomako et al. (2016) concerning the persistence of entrepreneurs. None of the studies discussed about optimism and persistence in the context of student participation in competitions. Similar research did investigate the effect of counterfactual thinking on persistence (Markman \& Mcmullen, 2006; Roese \& Epstude, 2017), but these studies study also used an experimental approach, with limited field context.

As such, this study aimed to fill gaps in research literature by investigating the role of dispositional optimism, upward and downward counterfactual thinking toward persistence among student competitors. This research focused on persistence in general, regardless of the type of competition and whether it involved individual participants or teams. Accordingly, the study did not analyze the different types of competitions on students. This reserch is crucial to understand persistence of student competitors in achieving their goals in a sustainable manner, which have which have contribution to knowledge gaps and in practice.

We proposed the following hypotheses:

$H^{0}$ Dispositional optimism, upward counterfactual thinking, and downward counterfactual thinking do not affect persistence of student competitors.

$H^{a}$ Dispositional optimism, upward counterfactual optimism, and downward counterfactual thinking play a role in persistence among students competitors.

\section{Literature review}

Persistence refers to actions to achieve a specific goal in the face of barriers, difficulties, and helplessness (Peterson \& Seligman, 2004). Constantin et al. (2012) defined persistence as endurance to perform difficult tasks during a significant period of time and during a discomforting situation. Conceptually, persistence is determined by numerous factors sourcing from social environment such as peers, teachers, trainers, or parents, the context of the tasks (Le Bars et al., 2009). Other scholars also found internal factors determining persistence such as self-motivation; motivation to meet basic psychological needs (need for power, competence, and relations) (Calvo et al., 2010). Others reported constructive anger against barriers to success, which was moderated by effective planning of goals (Schmitt et al., 2019) and optimism (Adomako et al., 2016; Carver et al., 2010; Icekson et al., 2014; Tenney et al., 2015) to also determine persistence.

Student persistence has been receiving attention in recent years. Researchers of this study have also conducted a preliminary online survey in May 2020 with 37 participants across 11 Indonesian universities to understand the feelings of student competitors following an unsuccessful attempt in a competition, as well as identify factors contributing to persistence. These participants were undergraduate or diploma students who have represented their faculty or University in a competition at least twice and has experienced failure or received an unfavorable outcome in this competition. We found that following a negative, or an undesired, outcome, most students expressed negative thoughts like feelings of incompetence $(24.3 \%)$ and thoughts about sacrifices that were not worth the results $(24.3 \%)$ over their failure in the competitions. Some thoughts also led to feelings that deterred persistence, for example disappointment $(43.2 \%)$ and sadness $(27 \%)$. Other feelings that were reported include laziness, fear, exhaustion, uselessness, lack of motivation, doubt, embarrassment, anger, boredom, and guilt. The finding was consistent with recent research findings from Czaja and Cummings (2009)and Xia (2018) that suggested that failure to achieve targets in competitions reduces 
Maria \& Wahyu || The Role of Dispositional

motivation to compete in future competition because it threatens self-competence and self-esteem.

\section{Optimism}

Our preliminary survey also found that personal characteristics influence persistence. Among other factors, optimism was the most influential characteristic (21\%). Optimism, conceptually referred to as dispositional optimism, is a person's tendency to be hopeful towards their future in all aspects regardless the type of event ("Optimism scale: Evidence of psychometric validity in two countries and correlations with personality", 2018). Optimism allows people to view the world in a positive light. People with positive attitudes tend to experience positive feelings and persist in achieving their goals, since they are hopeful that something good will come in the future (Chiesi et al., 2013). An optimistic person believes that they can overcome barriers while also viewing difficult tasks as challenging, not as threatening (Icekson et al., 2014). Therefore, optimists have higher persistence in achieving their goals (Jenaabadi et al., 2015). The role of optimism towards persistence is supported by findings from prior research. A study by Tenney et al. (2015) showed that optimism has a direct effect on persistence. Adomako et al. (2016) found that optimism influences persistence, though the effect was moderated by thinking style. In academic context, optimism is positively associated with persistence Carver et al. (2010). Research also suggests that optimism stimulates persistence in achieving a particular goal (Icekson et al., 2014).

\section{Counterfactual Thinking}

Research evidence showed that when competitors experience failure, they simulate outcomes in contrast to what actually occurred. This act of simulating past events is known as 'counterfactual thinking', which refers to simulation of thoughts contrasting with actual outcomes, for example thinking "what would happen if..." or "If only..." (Kray et al., 2010). Counterfactual thinking consists of two modes namely upward or downward counterfactual thinking.

Upward counterfactual thinking refers to a person's simulation of favorable outcomes compared to what actually occurred (Teigen \& Jensen, 2011). Upward other-referent refers to the tendency to simulate thoughts that other people may have an effect on producing a favorable outcome, while upward self-referent refers to the tendency to simulate thoughts about the self in affecting favorable outcomes. The upward non-referent is the tendency to attribute the simulation of an object which is not specifically tied to better outcomes (Rye et al., 2008). Meanwhile, downward counterfactual refers to the stimulation of thoughts that are worse than the actual outcomes (Payir \& Guttentag, 2016). This style of thinking consists of one mode, namely the downward non-referent which is the tendency to attribute simulations of an object which is not specifically tied to a worse outcome (Rye et al., 2008).

Counterfactual thinking also consists of two modes based on its functionality, namely reflection and evaluation. Reflection refers to simulation of alternatives without comparing with the reality, whereas evaluation concerns simulation of alternatives that compare with the actual occurence. This model makes predictions based on the combination of upward or downward counterfactual thinking and reflection and evaluation modes. Thus, people may adopt the upward reflection (UR) or simulation of better situations, without comparing actual situations, upward evaluation (UE) or simulation of better situations, by comparing with the actual situations, downward reflection (DR) or simulation of worse situations, without comparing with the actual situation, and downward evaluation (DE) or simulation of worse situations, by comparing with the actual situation. Counterfactual thinking using upward reflection (UR) and upward evaluation (UE) play role in improving persistence on prevention framing because UE focuses on a person's perseverance in making achievements by simulating better possibilities while preventing undesired outcomes when reflecting on what actually occurred. Downward reflection (DR) also increases the motivation to be aware and develop a plan to avoid undesired possibilities because of simulations of undesirable outcomes. However, downward evaluation has shown to not improve persistence (Markman \& McMullen, 2003; Markman \& Mcmullen, 2006; Smallman \& Roese, 2009). 
Maria \& Wahyu || The Role of Dispositional

\section{Method}

\section{Definition of terms}

We use the term 'student competitors' to refer to university students who participated in academic competitions to represent their universities or faculties. The student competitors in this research were those who had participated in competitions representing the faculties or universities at least twice. Given that, there is no literature to the research authors' knowledge that has established the exact frequency of competition participation to indicate persistence, we define a criterion of at least two participations may demonstrate student persistence. According to the Language Center of Indonesian Ministry of Education and Culture (2016), competition is "activities which assess speed of accomplishing a specific task (skills, agility, cleverness, etc.). The type of competitions included in this study is competitions organized by universities or other institutions which specifically target students. Some examples of the competitions addressed in this research are include debate, scientific writing, quiz, design, data analysis, scientific research, education media and sports.

\section{Participants}

The research used an online quantitative cross-sectional approach. The participants were recruited using non-probability sampling (Gravetter \& Forzano, 2018).This technique was appropriate in this study because it applies specific inclusion criteria, and thus it was crucial for researchers to conveniently obtain a sample that met the criteria (Vehovar et al., 2016).Inclusion criteria were: 1) being an undergraduate/diploma student; 2 ) has represented the university or faculty in competitions more than twice during the course of their studies in the same competition field; and 3) has experienced failure or obtaining negative outcomes in contrast to targets of competition as mentioned in point 2.

Two hundred and four participants were recruited through an online survey Google Forms by first asking for their consent in the informed consent section before filling out the scales. The generated link was shared through social media, such as Instagram, and personal chat from line, student groups, competition groups and groups of student competitors. The age range was 18-25 years old with a majority of the participants being 21 years of age (42.64\%). There were $36.76 \%$ male participants, $62.75 \%$ were female, and $0.49 \%$ were not identified. Students were from several disciplines; $25.98 \%$ were students of Faculty of Psychology, and the remaining were from 31 other Faculties, including Law, Politics, Economics, Engineering and so forth. Majority of participants were from Universitas Gadjah Mada (55.39\%), and the remaining came from 33 other universities, such as Universitas Indonesia, Universitas Negeri Yogyakarta, Universitas Padjajaran, Universitas Islam Indonesia and so forth. Majority of the participants were from the Special Region of Yogyakarta (63.14\%) and the remaining were from 20 other regions in Indonesia.

\section{Data collection procedure}

The study obtained an ethical approval from the Ethic Committee of Faculty Psychology UGM in $31^{s t}$ of August 2020. Before proceeding with data collection, we conducted a pilot study with 81 participants to evaluate the psychological scales used in this study. The scales were further assessed by three experts to establish content validity. Based on results of the pilot study and expert validation, the scales have met the criteria of content validity and sufficient standards from a psychometrical perspective.

There were four instruments used in this research, each of the scale is described in turn:

1. Dispositional optimism scale The Dispositional Optimism Scale was adapted from the Optimism Scale $(\alpha=0.93$; Brazil, $\alpha=0.85)$ ("Optimism scale: Evidence of psychometric validity in two countries and correlations with personality", 2018) and had been translated to Indonesian. The scale measured dispositional optimism with a single dimension consisting of eight favorable items which used a five-point Likert scale format ( $1=$ strongly disagree and $5=$ strongly agree) (Azwar, 1999). The higher score on favorable items indicated higher dispositional optimism, and vice versa. A sample of an item from this scale was "I believe that I will achieve my main goal". Based on the pilot study, this scale had a reliability of $\alpha=0.800$. 
2. Counterfactual thinking scale. The scale used to measure counterfactual thinking was the modified version of Counterfactual Thinking for Negative Event Scale (CTNES; $\alpha=0.73-0.84$ ) (Rye et al., 2008). The items were adapted to the context of student competitions and translated to Indonesian. The scale was divided into two sub-scales namely the Upward and Downward scale. The Upward Counterfactual Thinking Scale measured three aspects of the upward counterfactual thinking style, namely upward other referent, upward self-referent, and upward non-referent. Each aspect of the subscale consists of four items which used a five-point Likert response format (1=strongly disagree and $5=$ strongly agree) (Azwar, 1999). The higher the score, the higher the counterfactual thinking and vice versa. A sample of the item is "I imagined that the results of the competition was better than what actually played out." Based on the pilot study, the internal consistency reliability was $\alpha$ $=0.874$. The Downward Counterfactual Scale measured one aspect of the upward counterfactual thinking aspect, namely the downward non-referent aspect. The scale consisted of four items with a five-point Likert format ( $1=$ strongly disagree and $5=$ strongly agree) (Azwar, 1999). The higher the score, the higher the downward counterfactual thinking. A sample of this scale is "I feel lucky when thinking of worse competition outcomes". Based on the pilot study, this scale had an internal consistency reliability of $\alpha=0.874$.

3. Persistence The scale used to measure persistence was the Persistence Scale modified from the Motivational Persistence Scale $(\alpha=0.79)$ (Constantin et al., 2012). The scale was adapted for the context of the current study and translated into Indonesian. The Persistence Scale measured three aspects of persistence, such as long-term purposes pursuing (LTPP), current purposes pursuing (CPP) and recurrence of unattained purposes (RUP) with each aspect constituting a sub-scale. Each subscale consisted of four items with a five-point Likert format (1=strongly disagree and 5 $=$ strongly agree) (Azwar, 1999). The higher the score for each sub-scale, the higher the level of persistence, and vice versa. A sample item for this scale is "I am still motivated although preparation for the competition can take a very long time". Based on the pilot study, this scale had an internal consistency reliability of $\alpha=0.816$.

\section{Analysis}

The current study employed descriptive and inferential statistics using IBM SPSS 22. Test of assumptions were also conducted consisting of tests for normality, linearity, multicollinearity, and inter-correlation between variables. The hypothesis was tested using multiple regression.

\section{Results}

The results of the descriptive analyses, tests of assumption, and hypothesis tests, using multiple linear regression are presented in the following section. Analysis of descriptive statistics are presented in Table 1.

Table 1

Data descriptive

\begin{tabular}{lccccc}
\hline \multicolumn{1}{c}{ Variable } & $N$ & Min & Max & $M$ & $S D$ \\
\hline Dispositional Optimism & 204 & 10 & 40 & 32.51 & 5.044 \\
Upward Counterfactual Thinking & 204 & 12 & 57 & 37.46 & 8.895 \\
Downward Counterfactual Thinking & 204 & 4 & 20 & 11.57 & 3.636 \\
Persistence & 204 & 30 & 60 & 49.00 & 6.525 \\
\hline
\end{tabular}

Categorization of the four variables are presented in Table 2 to Table 5. Below are the categorization of the variable dispositional optimism (See Table 2). 
Table 2

Categorization of Dispositional Optimism

\begin{tabular}{cccc}
\hline Range & Category & Frequency & $(\%)$ \\
\hline $37<\mathrm{X}$ & High & 28 & 13.7 \\
$27<\mathrm{X}<37$ & Medium & 148 & 72.6 \\
$\mathrm{X}<27$ & Low & 28 & 13.7 \\
\hline Total & & 204 & 100
\end{tabular}

Based on categorization of the data in Table 2, we can see that dispositional optimism levels were mostly in the medium category $(72.6 \%)$.

Table 3

Categorization of Data of Upward Counterfactual Thinking

\begin{tabular}{cccc}
\hline Range & Category & Frequency & $(\%)$ \\
\hline $46<\mathrm{X}$ & High & 32 & 15.7 \\
$28<\mathrm{X}<46$ & Medium & 137 & 67.2 \\
$\mathrm{X}<28$ & Low & 35 & 17.1 \\
\hline & Total & 204 & 100 \\
\hline
\end{tabular}

Based on the categorization of the data in Table 5, we can see that persistence levels were mostly on the mild category $(67.2 \%)$.

Table 4

Categorization of Data of Downward Counterfactual Thinking

\begin{tabular}{cccc}
\hline Range & Category & Frequency & $(\%)$ \\
\hline $15<\mathrm{X}$ & High & 26 & 12.7 \\
$7<\mathrm{X}<15$ & Medium & 144 & 70.6 \\
$\mathrm{X}<15$ & Low & 34 & 16.7 \\
\hline & Total & 204 & 100 \\
\hline
\end{tabular}

Based on the categorization of the data in Table 4, we can see that downward counterfactual thinking levels are mostly on the medium category $(70.6 \%)$.

Table 5

Categorization of Data of Persistence

\begin{tabular}{|c|c|c|c|}
\hline Range & Category & Frequency & $(\%)$ \\
\hline $55<X$ & High & 35 & 17.2 \\
\hline $42<X<55$ & Medium & 132 & 64.7 \\
\hline$X<42$ & Low & 37 & 18.1 \\
\hline \multicolumn{2}{|c|}{ Total } & 204 & 100 \\
\hline
\end{tabular}

Furthermore, we conducted a test of the inter-correlation matrix which aimed to identify relationships between the independent and the dependent variable, one of the requirements of regression. If it was found that one or both of the independent variables were not related with the dependent variable ( $p>0.05)$, therefore the model would not meet the requirements of regression, and therefore the independent variable(s) in question can be eliminated from the model. The results of the inter-correlations between the independent and dependent variables showed that dispositional optimism $(\mathrm{r}=0.55 ; \mathrm{p}<0.05)$ and upward counterfactual thinking $(\mathrm{r}=0.27 ; \mathrm{p}<0.05)$ were correlated with persistence, while downward counterfactual thinking was not correlated with persistence $(\mathrm{r}=0.07 ; \mathrm{p}>0.05)$. Downward counterfactual thinking was potentially not an effective predictor, will be eliminated when performing stepwise regression analysis. The stepwise method was used to automatically eliminate variables which did not correlate with the dependent variable when performing the regression analyses. A complete presentation of the analyses can be seen in the Table 6 below. 
Table 6

Inter-correlation Matrix

\begin{tabular}{|c|c|c|c|c|}
\hline & $\begin{array}{l}\text { Dispositional } \\
\text { Optimism }\end{array}$ & $\begin{array}{l}\text { Upward } \\
\text { Counterfactual } \\
\text { Thinking }\end{array}$ & $\begin{array}{l}\text { Downward } \\
\text { Counterfactual } \\
\text { Thinking }\end{array}$ & Persistence \\
\hline $\begin{array}{l}\text { Dispositional } \\
\text { Optimism } \\
\text { Upward }\end{array}$ & 1 & & & \\
\hline $\begin{array}{l}\text { Counterfactual } \\
\text { Thinking } \\
\text { Downward }\end{array}$ & -0.039 & 1 & & \\
\hline $\begin{array}{l}\text { Counterfactual } \\
\text { Thinking }\end{array}$ & 0.111 & $0.256^{* *}$ & 1 & \\
\hline Persistence & $0.550^{* *}$ & $0.275^{* *}$ & 0.073 & 1 \\
\hline
\end{tabular}

**Correlation is significant at the 0.01 level (2-tailed)

Linearity tests were used to verify the assumption that the independent variable and the dependent variable have a linear relationship (Ghozali, 2016). Both variables were assumed to have a linear relationship when the F coefficient of linearity were significant $(\mathrm{p}<.0 .05)$ (Santoso, 2015). The test of linearity showed that dispositional optimism $(F=89.39 ; p<0.05)$ and upward counterfactual thinking $(F=17.06 ; p<0.05)$ both had a linear relationship with persistence. The results are presented in Table 7.

Table 7

Test of Linearity

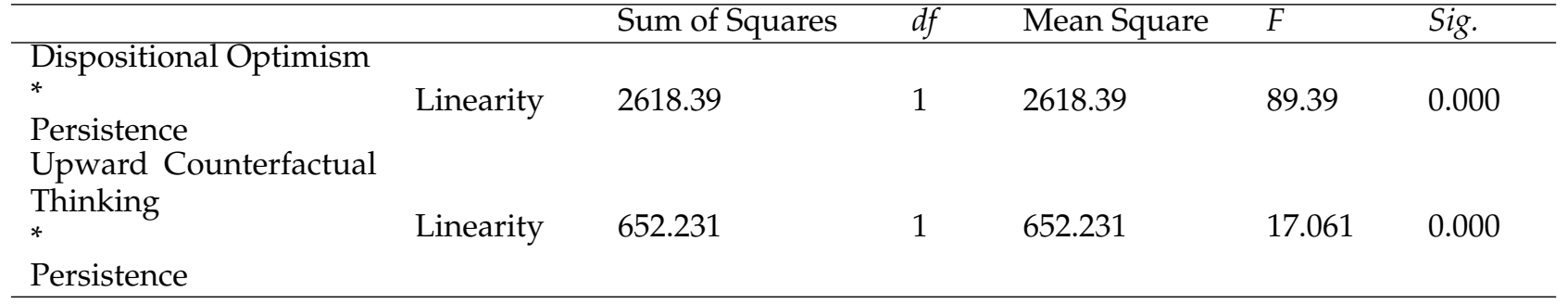

Normality testing for residuals was conducted to observe whether the residuals in the regression model were distributed normally (Hendry, 2019). The test showed that the residuals were normally distributed $(K S Z=0.038 ; p>0.05)$. Furthermore, we conducted a multi-collinearity test to observe whether the independent variables were related. Multicollinearity occurs when the VIF $>10$ with a tolerance value of $<0.1$ (Zainodin et al., 2011). The results of the analysis showed that multicollinearity was not evident among dispositional optimism and upward counterfactual thinking.

The hypothesis test used multiple regression analysis to understand the role of dispositional optimism and upward counterfactual thinking in predicting persistence. Downward counterfactual thinking was not included in the analysis using the stepwise method because it was not correlated with persistence. The results of the analysis are presented in Table 8 and Table 9.

Table 8

ANOVA

\begin{tabular}{lllll}
\hline Model & $R^{2}$ & $F$ & Sig. F Change & $p$ \\
\hline $\begin{array}{l}\text { Dispositional } \\
\text { Optimism, }\end{array} \begin{array}{c}\text { Upward } \\
\text { Counterfactual Thinking }\end{array}$ & 0.391 & 64.473 & 28.989 & $<0.01$
\end{tabular}


Based on Table 8, $R^{2}$ for both variables was 0.391 , which implied that dispositional optimism and counterfactual thinking played a role on persistence as large as $39.1 \%$ with a $(p)<0.01$.

Table 9

Multiple Linear Regression Analysis

\begin{tabular}{lllll}
\hline Model & $B$ & $T$ & $p$ & Zero order \\
\hline (Constant) & 17.220 & 6.065 & $<0.01$ & \\
$\begin{array}{l}\text { Dispositional } \\
\begin{array}{l}\text { Optimism, Upward } \\
\text { Counterfactual }\end{array}\end{array}$ & 0.727 & 10.200 & $<0.01$ & 0.550 \\
Thinking & 0.218 & 5.384 & $<0.01$ & 0.275 \\
\hline
\end{tabular}

The following is the regression equation: $Y=17.220+0.727 \mathrm{X} 1+0.218 \mathrm{X} 2$

Note: $Y=$ persistence

X1 $=$ Dispositional optimism

X2 = Upward counterfactual thinking

From the regression equation we can interpret this as an increase of 1 point of dispositional optimism leads to an increased persistence as large as 0.727 and each addition of one point of upward counterfactual thinking would lead to an increase of persistence as large as 0.218 . When both variables are absent, the value of persistence is 17.220. The regression equation also explains the size of each of the coefficients of the independent variables in predicting the dependent variable.

The results of the analysis showed that dispositional optimism and upward counterfactual thinking can explain 39.1\% variance of persistence and that the remaining variance can be explained by other variables beyond those studied in this research. To understand the contribution of each independent variable we calculated the beta coefficients of the zero-order correlation for each independent variable. We found that the regression model was dominated by the dispositional optimism variable with a coefficient of determination of $30.8 \%$ while upward counterfactual thinking was as large as $8.1 \%$.

The hypothesis test showed that only dispositional optimism and upward counterfactual thinking play a role in student persistence, while downward counterfactual thinking does not. Thus, we conclude that the hypothesis was rejected.

The researcher also conducted an independent sample's t-test to know the average difference of dispositional optimism, counterfactual thinking and persistence based on gender. The tests found that there were no significant differences between the average scores of dispositional optimism $(t=-1.41$; $p>0.05)$ among females $(M=32.13)$ and males $(M=33.16)$. The average scores for upward counterfactual thinking among female students $(M=36.86)$ and male students $(M=38.46)$ were also not significantly different $(t=-1.24 ; p>0.05)$. In line with these findings, no significant differences between persistence scores were found between $(t=-1.21 ; p>0.05)$ male $(M=48.58)$ and female students $(M=49.72)$. The results of the analyses are presented in the table below. 
Maria \& Wahyu || The Role of Dispositional

Table 10

Independent Sample's T-test based on Gender

\begin{tabular}{|c|c|c|c|c|}
\hline Variable & Gender & $M$ & $t$ & $p$ \\
\hline Dispositional Optimism & $\begin{array}{l}\text { Female } \\
\text { Male }\end{array}$ & $\begin{array}{l}32.13 \\
33.16\end{array}$ & -1.418 & 0.158 \\
\hline Upward Counterfactual Thinking & $\begin{array}{l}\text { Female } \\
\text { Male }\end{array}$ & $\begin{array}{l}36.86 \\
38.46\end{array}$ & -1.245 & 0.215 \\
\hline Persistence & $\begin{array}{l}\text { Female } \\
\text { Male }\end{array}$ & $\begin{array}{l}48.58 \\
49.72\end{array}$ & -1.214 & 0.226 \\
\hline
\end{tabular}

\section{Discussion}

This study was conducted to understand the role of dispositional optimism, upward and downward counterfactual thinking on persistence among student competitors. The results of the analysis showed that dispositional optimism and upward counterfactual thinking correlated simultaneously with persistence among student competitors, with dispositional optimism having a larger role compared to upward counterfactual thinking. Downward counterfactual thinking was not found to have a relationship with persistence among student competitors, and so this variable was not included in the regression analysis.

Reflection of obstacles when achieving goals may be the reason why dispositional optimism plays a significant role in predicting persistence among student competitors. Optimistic individuals view that their desired goal would be achieved in the future, and therefore the obstacles they encounter increase persistence in achieving their goal. Conversely, low optimism would prevent the sufficient hope that is needed to achieve their goals, and therefore drawbacks may lead individuals to either avoid or let go of their goals altogether (Jenaabadi et al., 2015; Segerstrom, 2007). This was supported by previous research concerning the role of optimism toward persistence which was moderated by thinking styles (Adomako et al., 2016). In addition, research conducted by (Tenney et al., 2015) showed that optimism directly affected persistence as shown in the present research. In the academic context, research from Carver et al. (2010) also showed that optimism had a positive association with persistence while Icekson et al. (2014) showed that optimism stimulated persistence in achieving goals.

The second mode, namely evaluation, refers to simulations concerning alternatives towards reality which compares with the actual event (Markman \& McMullen, 2003). REM suggests different mental simulations when a person engages in counterfactual thinking and that this affects the consequence of the counterfactual thinking. The first mode is reflection, which concerns simulations of alternatives toward reality without comparing with the actual event. The second mode, namely evaluations, refers to simulations concerning alternatives towards reality which compares with the actual event (Markman \& Mcmullen, 2006).

Reflection and evaluation are composed of upward evaluation and upward reflection. Upward evaluation (UE) concerns counterfactual thoughts that simulates better outcomes by comparing with an actual event, for example "If only I listened to what the coach/friend/family said, the results of the competition would have been better". (Item no.11). Upward reflection (UR) concerns counterfactual thinking that simulates better outcomes without comparing with any event, for example a runner up winner states "I imagined that the results would be better than this" (item number 8). The function of REM in counterfactual thinking can result in different feelings which can affect persistence. Positive feelings increase persistence in pleasant tasks although it can reduce persistence in achieving goals. Meanwhile, negative feelings can increase persistence in making achievements however it can reduce persistence in pleasant tasks (Markman et al., 2008). The presence of comparison of better outcomes among upward counterfactual thinking leads to negative feelings. These negative feelings can increase persistence in making achievement. Such dynamics explain why upward counterfactual thinking significantly plays a role in student persistence among student competitors which was shown in our research. 
Furthermore, the role of upward counterfactual thinking toward student competitor persistence can be explained by Regulatory Focus Theory. Based on Regulatory Focus Theory, there were two consequences from counterfactual thinking, namely promotion framing and prevention framing. A person with a promotion framing orientation focuses on growth, progress, and achievement, and so they sought strategies to achieve their desired goals. Meanwhile, a person with a prevention framing orientation focuses on protection, security, and responsibility and thus conducts strategies that avoid undesirable outcomes (Higgins, 2012).

Upward counterfactual thinking generally consists of upward reflection (UR) and upward evaluation (UE) and both have been proven to increase persistence in promotion framing. This occurs because upward counterfactual thinking generally triggers development of plans oriented toward achievement by simulating better outcomes. Meanwhile, upward evaluative counterfactual thinking specifically increases persistence in prevention framing. This is because there is focus on UE on a person's continuity in pursuing their goals by simulating other possibilities with better outcomes and prevention of undesired outcomes when reflecting on the actual course of events. Within the context of this research, goal attainment was indicated by the results of a competition which explained why upward counterfactual thinking plays a significant role on persistence of student competitors. The relationship between upward counterfactual thinking and persistence was supported by experimental work by Markman and Mcmullen (2006). Markman and Mcmullen (2006) and Roese and Epstude (2017) suggested that people who engage in upward reflective counterfactual thinking and upward evaluative thinking have high persistence.

Although dispositional optimism and upward counterfactual thinking both have a significant effect on persistence, the contribution of dispositional optimism was larger compared to upward counterfactual thinking. This can be explained by the presence of characteristics of upward counterfactual thinking that leads to negative feelings. Such negative feelings are like a double-edged sword: It may increase persistence through promotion framing by upward counterfactual thinking comprehensively as well as prevention framing by upward evaluation counterfactual thinking. However, negative feelings can also lead to reduced persistence toward the tasks (Steinberg et al., 2013). In addition, negative feelings that increase continuously as a result of comparison with better outcomes and a person's inability to separate from negative situations can lead to depression (Broomhall et al., 2017).

The final independent variable, downward counterfactual thinking, was not included in the regression analyses because it did not have a significant role toward student competitors' persistence. Similar to upward counterfactual thinking, the Reflection and Evaluation Model (REM), also explains why there was no significant effect of downward counterfactual thinking on persistence. The REM model divides downward counterfactual thinking into two functions, namely downward evaluation and downward reflection. Downward evaluation (DE) refers to counterfactual thinking that simulates worse outcomes by using simulations as a comparison of reality for example "I feel relieved when imagining worse outcomes" (item number 5). Such simulations cause a person to feel content with the status quo and so leads to positive feelings. Finally downward reflection (DR), concerns counterfactual thinking that simulates worse outcome without making any comparisons for example "I imagined that the result would be way worse than what actually occurred" (Item number 1). Such simulations may lead a person to feel that worse outcomes may have occurred which would lead to negative feelings. Similar to upward counterfactual thinking, play a role in persistence. Positive feelings elicited by DE reduce persistence in achieving goals. While negative feelings elicited by DR increase persistence in achieving goals (Markman \& McMullen, 2003; Markman \& Mcmullen, 2006; Roese \& Epstude, 2017) such findings were not supported in the current research.

In addition, based on Regulatory Focus Theory, downward reflection was proved to increase persistence through prevention framing. This occurs because of simulations of negative outcomes that can occur when engaging in DR counterfactual thinking which leads to motivations to be cautious and plans to avoid undesirable possibilities. Meanwhile, DE, becomes one of the types of counterfactual thoughts which does not increase persistence because of comparisons between reality and possible worse outcomes that may occur. This may lead a person to feel content with the status quo and therefore not motivated to achieve a better set of outcomes or may avoid situations which may lead to worse outcomes. 
Despite these findings, the results of the research showed that downward counterfactual thinking - consisting of DE and DR - does not significantly play a role in persistence. The divergent findings with past studies may have been caused by different study designs. Previous research used an experimental design, while this research used a correlational survey design. The scale which was used namely the Downward Counterfactual Thinking Scale may have not represented the DR Counterfactual thinking since it only consisted of 1 item. In addition, other items in the scale consisted of DE counterfactual thinking style, which was conceptually not shown to increase persistence. This explains why the variables of downward counterfactual thinking did not have any effect on persistence.

Additional analyses showed that there were no differences between male and female student competitors in their dispositional optimism, counterfactual thinking, and persistence. Concerning persistence among male and female students, this finding was inconsistent with other findings concerning one determinant of persistence, namely motivation for achievement. Males have been shown to have higher motivation to achievement in non-academic settings compared to female students, while females had higher motivation to make achievements in academic activities than male students (A. J. Martin, 2004; Shekhar \& Devi, 2012). However, there are other research that found no significant differences of motivation of achievement among male and female students (Sarangi, 2015). which support the current research. The absence of gender difference may be associated with the inclusion characteristics of the participants as students who have participated in a competition at least twice and have experienced a defeat in the competition. The two criteria were very specific and people with these characteristics in general have a high need for achievement. Since need for achievement becomes one of the factors of persistence (Jabeen \& Ahmad, 2013) this explains why participants in general had the same levels of persistence and it was not affected by gender.

Concerning dispositional optimism, the findings were also different from other research which found that males had higher levels of optimism compared to females (Bjuggren \& Elert, 2019). Conversely, other findings showed that the level of optimism for women was higher than for men (Bastianello et al., 2014; Colby \& Shifren, 2013; Orejudo et al., 2012). In line with this research, past research conducted by (Johnson, 2018) also showed that there was no significant difference of optimism between men and women. This can be explained by the changing roles and stereotypes towards gender among $\mathrm{Y}$ generation, who were the majority of the participants in this research. Conceptually, the $\mathrm{Y}$ generations are more open, confident, and persistent in meeting their life needs (C. A. Martin, 2005), have less restrictive gender role as compared to past generations, and have more self-esteem and optimism when interacting with other humans, and thus optimism was no longer constrained by gender (Orejudo et al., 2012).

Finally, concerning upward counterfactual thinking, the literature review showed that there was no study that discusses differences in terms of upward counterfactual thinking according to gender. Therefore, the findings of this research serve as a novel contribution for new theory that opens new avenues for research.

\section{Conclusion}

This research examined the role of dispositional optimism, upward counterfactual thinking, and downward counterfactual thinking on persistence among student competitors. Three novel contributions were made; namely this research is the first to study persistence within the context of student competition, using a correlational approach to measure the role of optimism toward persistence and in the real context, as well as combine the role of dispositional optimism, upward counterfactual thinking, and downward counterfactual thinking toward persistence. The researcher concludes that dispositional optimism and upward counterfactual thinking simultaneously play a role in predicting persistence, while downward counterfactual thinking was not proven to have an effect on persistence.

Two implications arise from this research. First, theoretically, the findings are expected to give a contribution to the study of social psychology concerning dispositional optimism among students and counterfactual thinking following a defeat in a competition. Second, in a practical sense, the findings 
can be used for student competitors and their trainers. For student competitors, the results are expected to help improve persistence by forming dispositional optimism and upward counterfactual thinking, for example sharing experiences with seniors or with other student competitors, particularly for students who are successful. Student competitors are expected to give feedback and support to as well as comparison to a better situation between each other. For the trainer, this can be made as a discourse to help improve student persistence when guiding students by forming dispositional optimism and upward counterfactual thinking, as an example telling success stories. There were four limitations from the current research that may benefit future research. First, in contrast from past research, the results showed that downward counterfactual thinking does not play a role in persistence and so future research should evaluate the measure of downward counterfactual thinking. Future research should also involve representative participants and investigate other important variables to understand the factors beyond the ones analysed in this research which may have a larger effect on persistence. Second, in this research, the role of counterfactual thinking was studied using a survey approach, not an experimental approach, and so we cannot determine with certainty whether the effects of the independent variables on persistence were causal. Therefore, future research investigating the role of counterfactual thinking on persistence may try to use an experimental approach. Finally, no studies exist concerning the total number of competitions that are followed and its relation to persistence which can become an opportunity for future research to investigate with greater depth.

\section{Recommendation}

Based on the findings of this study, the research recommends that student competitors should increase their optimism by developing positive thoughts concerning future competitions, as well as form upward counterfactual thinking by thinking of better outcomes in subsequent competitions. The trainers are advised to form an atmosphere that supports optimism and helps students to develop upward counterfactual thinking.

\section{Acknowledgement}

Authors would like to thank every party involved in the process of data collection, the questionnaire distributors and the respondents

Funding

This research received no external funding.

\section{Authors' contribution}

The first author developed the study concept and wrote the entire manuscript. Second author analyzed the data and reviewed the manuscript.

\section{Conflict of interest}

The first author developed the study concept and wrote the entire manuscript. Second author analyzed the data and reviewed the manuscript.

\section{Orcid ID}

Maria Gracia Amara Pawitra 0000-0001-7542-5685

Wahyu Jati Anggoro 0000-0001-7858-303X 
Maria \& Wahyu || The Role of Dispositional

\section{References}

Adomako, S., Danso, A., Uddin, M., \& Damoah, J. O. (2016). Entrepreneurs' optimism, cognitive style and persistence. International Journal of Entrepreneurial Behaviour and Research, 22(1), 84-108. https: / / doi.org/10.1108/IJEBR-07-2015-0158

Aspinwall, L. G., \& Richter, L. (1999). Optimism and self-mastery predict more rapid disengagement from unsolvable tasks in the presence of alternatives. Motivation and Emotion, 23(3), 221-245. https://doi.org/10.1023/A:1021367331817

Azwar, S. (1999). Penyusunan skala psikologi. Yogyakarta, Pustaka Pelajar.

Barney, R. K. (1996). Resistance, persistence, providence: The 1932 los angeles olympic games in perspective. Research Quarterly for Exercise and Sport, 67(2), 148-160. https:/ / doi.org/10.1080/ 02701367.1996.10607939

Bastianello, M., Pacico, J., \& Hutz, C. (2014). Optimism, self-esteem and personality: Adaptation and validation of the brazilian version of the revised life orientation test (lot-r) micheline roat bastianello - universidade federal do rio grande do sul, porto alegre, brasil. REVISTA PSICO-USF, 19, 523-531. https:/ / doi.org/10.1590/1413-82712014019003014

Bjuggren, C. M., \& Elert, N. (2019). Gender differences in optimism. Applied Economics, 51(47), 5160-5173. https://doi.org/10.1080/00036846.2019.1610714

Brecht, A. A., \& Burnett, D. D. (2019). Advising Student-Athletes for Success: Predicting the Academic Success and Persistence of Collegiate Student-Athletes. NACADA Journal, 39(1), 49-59. https: / /doi.org/10.12930/nacada-17-044

Broomhall, A. G., Phillips, W. J., Hine, D. W., \& Loi, N. M. (2017). Upward counterfactual thinking and depression: A meta-analysis. Clinical Psychology Review, 55, 56-73. https: / / doi.org/10.1016/j. cpr.2017.04.010

Calvo, T. G., Cervelló, E., Jiménez, R., Iglesias, D., \& Murcia, J. A. M. (2010). Using self-determination theory to explain sport persistence and dropout in adolescent athletes. Spanish Journal of Psychology, 13(2), 677-684. https:/ / doi.org/10.1017/S1138741600002341

Carver, C. S., Scheier, M. F., \& Segerstrom, S. C. (2010). Optimism. Clinical Psychology Review, 30(7), 879-889. https://doi.org/10.1016/j.cpr.2010.01.006

Chiesi, F., Galli, S., Primi, C., Innocenti Borgi, P., \& Bonacchi, A. (2013). The accuracy of the Life Orientation Test-Revised (LOT-R) in measuring dispositional optimism: Evidence from item response theory analyses. Journal of Personality Assessment, 95(5), 523-529. https:/ /doi.org/10. 1080/00223891.2013.781029

Colby, D. A., \& Shifren, K. (2013). Optimism, mental health, and quality of life: A study among breast cancer patients. Psychology, Health and Medicine, 18(1), 10-20. https: / / doi . org / 10.1080 / 13548506.2012.686619

Constantin, T., Holman, A., \& Hojbotǎ, A. M. (2012). Development and validation of a motivational persistence scale. Psihologija, 45(2), 99-120. https:/ / doi.org/10.2298/PSI1202099C

Czaja, R. J., \& Cummings, R. G. (2009). Designing Competitions: How To Maintain Motivation For Losers. American Journal of Business Education (AJBE), 2(9), 91-98. https: / / doi.org/10.19030/ ajbe.v2i9.4614

Ghozali, I. (2016). Aplikasi analisis multivariate dengan program IBM SPSS 23. Semarang, BPFE Universitas Diponegoro.

Gravetter, F. J., \& Forzano, L.-A. B. (2018). Research Methods for the Behavioral Science (6th). Cengage Learning.

Hendry, R. S. M. (2019). Analisis Faktor-Faktor Yang Mempengaruhi Dividend Payout Ratio Pada Perusahaan Manufaktur Yang Terdaftar Di Bei. Ecobisma (Jurnal Ekonomi, Bisnis Dan Manajemen), 2(1), 1-11. https://doi.org/10.36987/ecobi.v2i1.57

Higgins, E. T. (2012). Regulatory focus theory. Handbook of Theories of Social Psychology: Volume 1, 483-504. https:/ /doi.org/10.4135/9781446249215.n24

Huang, W., Yang, Y.-J., Hu, H., Zhang, S.-B., \& Cao, K.-F. (2016). Evidence for the role of cyclic electron flow in photoprotection for oxygen-evolving complex. Journal of Plant Physiology, 194, 54-60. https:/ /doi.org/10.1016/j.jplph.2016.02.016 
Maria \& Wahyu || The Role of Dispositional

Icekson, T., Roskes, M., \& Moran, S. (2014). Effects of optimism on creativity under approach and avoidance motivation. Frontiers in Human Neuroscience, 8(1 FEB), 1-6. https: / / doi .org / 10. 3389/fnhum.2014.00105

Jabeen, S., \& Ahmad, M. (2013). A Study on Need Achievement of High and Low Achievers. Journal of Education and Practice, 4(4), 225-235.

Jenaabadi, H., Ahani, M. A., \& Sabaghi, F. (2015). Examining the Relationship of Optimism and Emotion Regulation Strategies with General Health among Students of University of Sistan and Baluchestan. Health, 07(07), 865-872. https://doi.org/10.4236/health.2015.77102

Johnson, A. C. (2018). An examination of optimism between gender, race, and school classification of millennial students-An exploratory study (Doctoral dissertation). Georgia Southern University.

Kamusoko, S. D., \& Pemberton, C. L. A. (2013). Student-Athlete Wellbeing and Persistence: An In-depth Look at Student-Athlete Perceptions. Journal for the Study of Sports and Athletes in Education, 7(1), 41-61. https://doi.org/10.1179/1935739713z.0000000003

Kray, L. J., George, L. G., Liljenquist, K. A., Galinsky, A. D., Tetlock, P. E., \& Roese, N. J. (2010). From What Might Have Been to What Must Have Been: Counterfactual Thinking Creates Meaning. Journal of Personality and Social Psychology, 98(1), 106-118. https://doi.org/10.1037/a0017905

Language Center of Indonesian Ministry of Education and Culture. (2016). Great Dictionary of the Indonesian Language. Indonesian Ministry of Education; Culture.

Le Bars, H., Gernigon, C., \& Ninot, G. (2009). Personal and contextual determinants of elite young athletes' persistence or dropping out over time. Scandinavian Journal of Medicine and Science in Sports, 19(2), 274-285. https://doi.org/10.1111/j.1600-0838.2008.00786.x

Markman, K. D., \& McMullen, M. N. (2003). A reflection and evaluation model of comparative thinking. Personality and Social Psychology Review, 7(3), 244-267. https: / / doi.org / 10.1207 / S15327957PSPR0703_04

Markman, K. D., \& Mcmullen, M. N. (2006). Counterfactual thinking and regulatory fit. Judgment and Decision Making, 1(NA), 98-107.

Markman, K. D., McMullen, M. N., \& Elizaga, R. A. (2008). Counterfactual thinking, persistence, and performance: A test of the Reflection and Evaluation Model. Journal of Experimental Social Psychology, 44(2), 421-428. https:// doi.org/10.1016/j.jesp.2007.01.001

Martin, A. J. (2004). School motivation of boys and girls: Differences of degree, differences of kind, or both? Australian Journal of Psychology, 56(3), 133-146. https : / / doi . org / 10 . 1080 / 00049530412331283363

Martin, C. A. (2005). From high maintenance to high productivity: What managers need to know about Generation Y. Industrial and Commercial Training, 37(1), 39-44. https: / / doi .org / 10.1108 / 00197850510699965

Nes, L. S., Segerstrom, S. C., \& Sephton, S. E. (2005). Engagement and arousal: Optimism's effects during a brief stressor. Personality and Social Psychology Bulletin, 31(1), 111-120. https:/ / doi. org/10.1177/0146167204271319

Optimism scale: Evidence of psychometric validity in two countries and correlations with personality. (2018). Personality and Individual Differences, 134(June), 245-251. https: / / doi.org / 10.1016/j. paid.2018.06.030

Orejudo, S., Puyuelo, M., Fernández-Turrado, T., \& Ramos, T. (2012). Optimism in adolescence: A cross-sectional study of the influence of family and peer group variables on junior high school students. Personality and Individual Differences, 52(7), 812-817. https://doi.org/10.1016/j.paid. 2012.01.012

Payir, A., \& Guttentag, R. (2016). "It could have been worse": Developmental change in the use of a counterfactual consoling strategy. Journal of Experimental Child Psychology, 148, 119-130. https: //doi.org/10.1016/j.jecp.2016.04.001

Peterson, C., \& Seligman, M. E. P. (2004). Character strengths and virtues: A classification and handbook. New York, Oxford University Press.

Reisinger, S. H. (2016). Using a revised theory of student departure to understand student athlete persistence by, 181. https: / / iro.uiowa.edu / discovery / fulldisplay / alma9983776710702771 / 01IOWA_INST:ResearchRepository\%0Ahttps://ir.uiowa.edu / cgi / viewcontent.cgi? article= $6551 \% 5$ C\&context=etd 
Maria \& Wahyu || The Role of Dispositional

Roese, N. J., \& Epstude, K. (2017). The Functional Theory of Counterfactual Thinking: New Evidence, New Challenges, New Insights (1st ed., Vol. 56). Elsevier Inc. https:/ / doi.org/10.1016/bs.aesp.2017. 02.001

Rottensteiner, C., Tolvanen, A., Laakso, L., \& Konttinen, N. (2015). Youth Athletes' Motivation, Perceived Competence, and Persistence in Organized Team Sports. Journal of Sport Behavior, 38(4), 432-449. http://search.ebscohost.com/login.aspx?direct=true\%5C\&db=s3h\%5C\&AN= $110663396 \% 5$ C\&site $=$ ehost-live

Rye, M. S., Cahoon, M. B., Ali, R. S., \& Daftary, T. (2008). Development and validation of the counterfactual thinking for negative events scale. Journal of Personality Assessment, 90(3), 261-269. https://doi.org/10.1080/00223890701884996

Santoso, S. (2015). Menguasai statistik multivariat. Jakarta, PT Elex Media Komputindo.

Sarangi, C. (2015). Achievement Motivation of the High School Students : a Case Study Among Different Communities of Goalpara District of Assam. Journal of Education and Practice, 6(19), 140-145.

Schmitt, A., Gielnik, M. M., \& Seibel, S. (2019). When and how does anger during goal pursuit relate to goal achievement? The roles of persistence and action planning. Motivation and Emotion, 43(2), 205-217. https://doi.org/10.1007/s11031-018-9720-4

Segerstrom, S. C. (2007). Optimism and resources: Effects on each other and on health over 10 years. Journal of Research in Personality, 41(4), 772-786. https:/ / doi.org/10.1016/j.jpp.2006.09.004

Shekhar, C., \& Devi, R. (2012). Achievement Motivation across Gender and Different Academic Majors. Journal of Educational and Developmental Psychology, 2(2), 105-109. https: / / doi.org / 10.5539 / jedp.v2n2p105

Smallman, R., \& Roese, N. J. (2009). Counterfactual thinking facilitates behavioral intentions. Journal of Experimental Social Psychology, 45(4), 845-852. https://doi.org/10.1016/j.jesp.2009.03.002

Steinberg, M. L., Ph, D., Williams, J. M., \& D, M. (2013). State , But Not Trait , Measures of Persistence Are, 1(July), 584-588.

Steinmayr, R., \& Spinath, B. (2009). The importance of motivation as a predictor of school achievement. Learning and Individual Differences - LEARN INDIVID DIFFER, 19, 80-90. https:/ / doi.org/10. 1016/j.lindif.2008.05.004

Teigen, K. H., \& Jensen, T. K. (2011). Unlucky victims or lucky survivors? Spontaneous counterfactual thinking by families exposed to the tsunami disaster. European Psychologist, 16(1), 48-57. https: //doi.org/https://psycnet.apa.org/doi/10.1027/1016-9040/a000033

Tenney, E. R., Logg, J. M., \& Moore, D. A. (2015). (Too) optimistic about optimism: The belief that optimism improves performance. Journal of Personality and Social Psychology, 108(3), 377-399. https://doi.org/10.1037/pspa0000018

Vehovar, V., Toepoel, V., \& Steinmetz, S. (2016). Non-probability sampling.

Xia, L. (2018). Luck or Skill : How Women and Men Attribute Successes and Failures.

Zainodin, H., Noraini, A., \& Yap, S. (2011). An Alternative Multicollinearity Approach in Solving Multiple Regression Problem. Trends in Applied Sciences Research, 6(11), 1241-1255. https: / / doi.org/10.3923/tasr.2011.1241.1255 